\title{
Expanding the Small Molecular Toolbox to Study Big Biomolecular Machines
}

\author{
Martin Lochner*
}

\begin{abstract}
Ion channels are transmembrane protein complexes that are found in virtually all cells. They fulfill a crucial physiological function by facilitating communication between and within cells. Consequently, impaired channel function, e.g. due to mutations, often has profound physiological effects. Their central role in cell-to-cell communication makes ion channels formidable drug targets, albeit their transmembrane nature often hampers efforts to obtain high resolution structures and hence impedes drug discovery. Decades of electrophysiology and molecular biology studies have made critical contributions to our understanding of ion channel structure and function. Small organic compounds, acting as either agonist or antagonist, have played vital roles in such studies and in recent years these molecular tools have become more sophisticated. Decorated with fluorescent, photoaffinity and/or affinity tags small molecular tools enable imaging, binding site mapping and isolation of biomolecular targets. Here, some of the methodologies employed in the context of ion channels are discussed and highlighted with representative examples.
\end{abstract}

Keywords: Affinity reagent · Covalent protein modification · Fluorescent probe $\cdot$ Ion channel $\cdot$ Photoaffinity tag

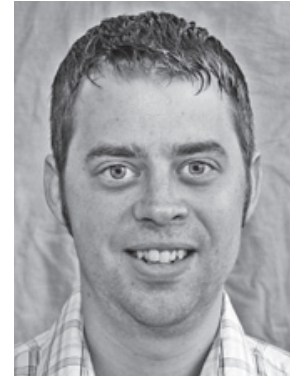

Martin Lochner received his Diploma in Chemistry from the University of Zürich in 1998. His diploma thesis concerned the synthesis of unnatural polyamines and was carried out in the group of Prof. Manfred Hesse. Martin Lochner then moved to the University of Basel and completed his PhD studies under the guidance of Prof. Wolf-D. Woggon in 2003 working on iron porphyrins as mimics for P450 enzymes. He then joined Prof. Ian Paterson's lab in the Department of Chemistry at the University of Cambridge (UK) as a postdoctoral research fellow where he worked on the total synthesis of Peloruside A. This was followed by a postdoctoral stay in the group of Dr. Sarah Lummis in the Department of Biochemistry at the University of Cambridge. In her group Martin Lochner studied the structure and function of mutant serotonin $5-\mathrm{HT}_{3}$

\footnotetext{
${ }^{\star}$ Correspondence: Prof. Dr. M. Lochner Departement für Chemie \& Biochemie Universität Bern

Freiestrasse 3

$\mathrm{CH}-3012$ Bern

Tel.: +41316313311

Fax: +41316314272

E-mail: martin.lochner@dcb.unibe.ch
}

receptors. He then joined the Chemistry Department at the University of Warwick (UK) as a Lecturer in Chemical Biology in 2006 where he started to develop his independent research. In January 2010 Martin Lochner joined the Department of Chemistry and Biochemistry at the University of Bern after being awarded a Swiss National Science Foundation Professorship.

\section{Introduction}

Ion channels are transmembrane protein complexes which allow the passage of ions through biological membranes. They are not simple holes; ion channels are complex machines that can conduct ions with excellent specificity, in huge quantities ( $10^{6}$ ions/sec), at speeds close to the limit of diffusion, under very tight regulation. Ion channels are essential for important physiological processes such as nerve and muscle excitation, hormone secretion, cell proliferation, sensory transduction, learning and memory and regulation of blood pressure, to name just a few. The crucial physiological importance becomes apparent when ion channel function is impaired. Mutations in over 60 ion-channel genes are now known to cause human disease (so-called channelopathies). ${ }^{[1]}$ Due to their important functional role ion channels are attractive targets for drug therapy; small molecules which either activate (agonists) or block (antagonists) channel function can be used to control psychiatric disorders and other diseases.

The ligand-gated ion channel (LGIC) superfamily of neurotransmitter receptors are responsible for rapid transmission of nerve impulses at synapses. These LGICs work when small organic molecules (neurotransmitters) are released into the synaptic cleft from the pre-synaptic cell and bind to LGICs on the surface of the postsynaptic cell, resulting in a conformational transition from a non-conducting 'closed' state to a conducting 'open' state. High ion flux across the cell membrane in the open channel state changes the membrane potential, which triggers further events and ultimately leads to the generation of a new action potential. In the continued presence of agonist the receptor then enters a structurally distinct non-conducting 'desensitised' state.

Receptors (R) of the Cys-loop family constitute a major class of receptor-coupled ion channels which includes nicotinic acetylcholine (nACh), serotonin (5-hydroxytryptamine, 5-HT) type $3\left(5-\mathrm{HT}_{3}\right)$, $\gamma$-aminobutyric acid type A (GABA) and glycine receptors. ${ }^{[2]}$ These LGICs consist of five pseudo-symmetrically arranged subunits; each subunit comprises a large extracellular $\mathrm{N}$-terminal domain that is responsible for agonist binding, four transmembrane domains (termed M1-M4) that surround a central ion conducting pore, and a large intracellular loop between M3 and M4 that influences channel conductance and mediates the actions of intracellular messengers (Fig. 1). Note that the agonist binding site is located at the interface of two adjacent subunits and consequently homopentamers, such as the $\alpha 7 \mathrm{nACh}$ and $5-\mathrm{HT}_{3} \mathrm{AR}$ subtypes, potentially possess five ligand binding sites. 


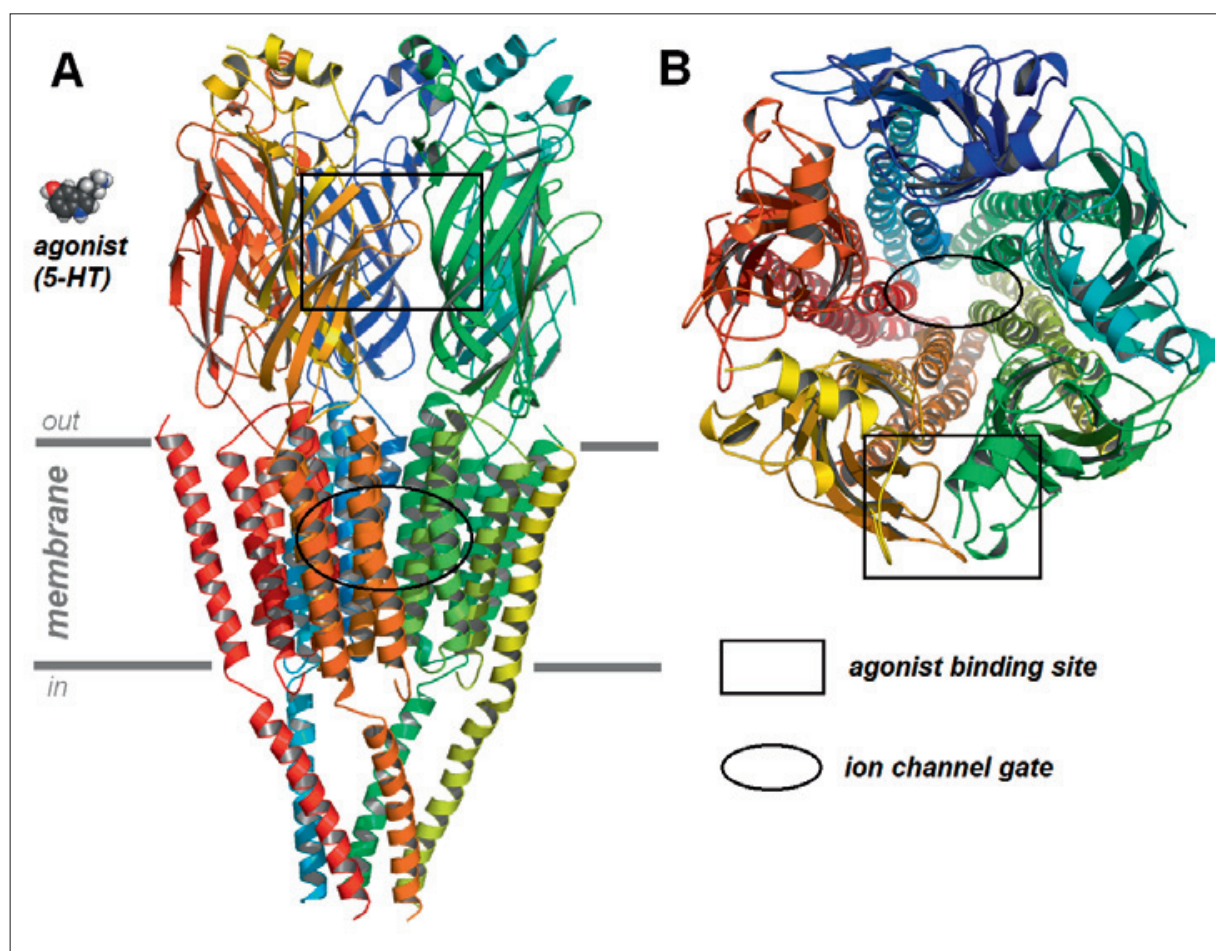

Fig. 1. Side view $(A)$ and top view $(B)$ of a $5-H_{3} A R$ homology model generated using the cryoelectron microscopy structure of the nAChR (PDB ID: 2bg9) as a template. Shown are the $\mathrm{N}$-terminal extracellular domains ( $\beta$-sheets), the transmembrane domains ( $\alpha$-helices, M1-M4), one putative agonist binding site (black box) at the interface of two adjacent subunits and the ion channel gate (black oval). Agonist (5-HT) is shown to scale, dark grey bars indicate the limits of the cell membrane. The long intracellular M3-M4 loop was not resolved in the cryo-EM structure.

Transmembrane proteins, including LGICs, are notoriously difficult to crystallise and it is still very challenging to solve their exact three-dimensional structure by $\mathrm{X}$-ray. In recent years structural insight of Cys-loop receptors has been gained from high resolution structures of homologous acetylcholine binding proteins (AChBPs), engineered $\mathrm{nAChR}$ subunits, homologous bacterial receptors and cryo-electron microscopy data of the nAChR. ${ }^{3]}$ Despite these snippets of structural information it is far from understood how small organic molecules (e.g. neurotransmitters, drugs) are able to activate or block these huge multi-subunit proteins. Intriguingly, the agonist binding site and the ion channel 'gate' (the narrowest region of the channel pore in the middle of the transmembrane domain) are more than $50 \AA$ apart (Fig. 1). The exact mechanism which efficiently couples the ligand-binding event to the gating (channel opening) event is heavily debated and various models have been put forward in the literature. LGICs are highly dynamic molecules and exist in at least three conformationally distinctive states (open, closed, desensitised). In addition, Cys-loop LGICs show cooperative agonist binding and typically two agonists need to bind in order to fully open the channel. Albeit informative, crystal structures can only provide snap shots of ion channel dynamics and in many cases it is very difficult to assign a (homologous) crystal structure to a certain channel state. Given that homology models ${ }^{[4]}$ are generated using published structures as templates, they have to be treated with caution and often require labour-intensive validation by experimental methods (i.e. receptor mutagenesis). Hence, homology models often fail to explain LGIC function and they are too inaccurate to allow structurebased drug design. Furthermore, it is very difficult to predict how a molecule with a new structure will interact with its receptor target (will it behave as an agonist, antagonist, partial agonist, inverse agonist, allosteric modulator or an open pore blocker?). It is clear that designing new drugs targeted to LGICs is very challenging and medicinal chemists in this area are literally trying to hit a moving target.

The Cys-loop LGICs have been the focus of numerous functional studies using a vast array of molecular biology techniques. For such studies, the receptors must be expressed in eukaryotic cells which have the necessary cell machinery for post-translational modifications (e.g. glycosylation) and assembly of the receptor subunits, and their transport to the cell surface. Commonly, wild type and mutant receptors are studied functionally using pharmacological tools such as endogenous agonists, drugs or toxins which either evoke activation or inactivation. In particular, $\left[{ }^{3} \mathrm{H}\right]$-labelled antagonists (radioligands) are widely used to investigate ligand binding behaviour of wild type and mutant receptors (radioligand binding assay). Radioligands can also be utilised to determine binding affinities of novel compounds for a particular receptor: the target LGIC is incubated with the radioligand which is displaced by adding increasing concentrations of the probe compound in a competition assay. The affinity of the probe compound $\left(K_{\mathrm{i}}\right.$ or $\left.\mathrm{IC}_{50}\right)$ can then be extracted from the corresponding dose-inhibition curve. Electrophysiology is considered to be the gold standard for characterising ion channel function. For this method to be used, the ion channels must be embedded in the membrane of a living cell with a resting membrane potential, such as mammalian cells (for patch-clamp) or oocytes from the frog Xenopus leavis (for two-electrode voltage clamp). Pharmacological tools (agonists or antagonists) are routinely used in electrophysiology studies in order to investigate gating kinetics, blockage and desensitisation of ion channels.

Undoubtedly, decades of molecular biology and electrophysiology studies have made critical contributions to our understanding of Cys-loop and other ion channel receptor structure and function but these methods also have clear limitations. There are numerous receptors which are very difficult to clone or isolate from native tissue. Many informative studies of ion channel receptors which can be expressed routinely have been performed using site-directed mutagenesis. However, this methodology suffers from the limited structural variation provided by the twenty natural amino acids and some of these amino acid replacements are far from subtle. In many areas of ion channel research better pharmacological tools are desperately needed because available compounds are lacking potency and ion channel subtype selectivity.

\section{Fluorescent Ligands}

Fluorescence has long been used to visualise cell biology and particularly small organic fluorophores covalently attached to biological macromolecules provide an efficient and very sensitive way to probe molecular processes in their environment. Alternatively, the fluorophore can also be linked to a ligand which is interacting with the protein of interest. Radioligand-based binding assays suffer from several drawbacks including radioactive waste disposal, special safety training and labs, environmental monitoring and regulatory agency documentation. Fluorescence-based methods, particularly fluorescence polarisation methods, have emerged as versatile alternatives with 


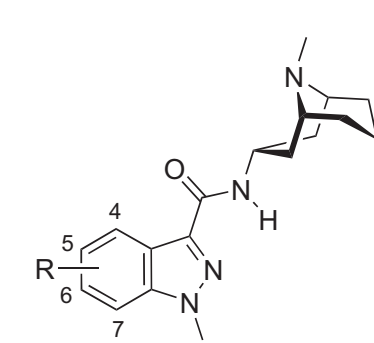

$1, \mathrm{R}=\mathrm{H}$, granisetron

2a-c, $\mathrm{R}=4-\mathrm{OH}, 4-\mathrm{OMe}, 4-\mathrm{OBn}$

3a-c, R = 5-OH, 5-OMe, 5-OBn

4a-c, R = 6-OH, 6-OMe, 6-OBn

5a-c, R = 7-OH, 7-OMe, 7-OBn

Fig. 2. 5- $\mathrm{HT}_{3} \mathrm{AR}$ antagonist $\mathbf{1}$ and derivatives $\mathbf{2}-\mathbf{7}$ synthesised for structure-activity study.

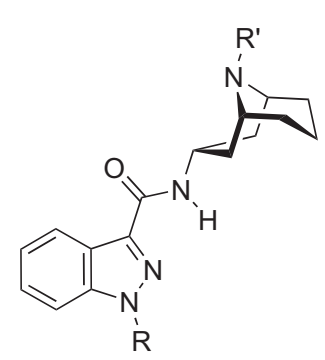

6, $\mathrm{R}=\mathrm{Me}, \mathrm{R}^{\prime}=\mathrm{Bn}$

7, $\mathrm{R}=\left(\mathrm{CH}_{2}\right)_{3} \mathrm{NH}_{2}, \mathrm{R}^{\prime}=\mathrm{Me}$

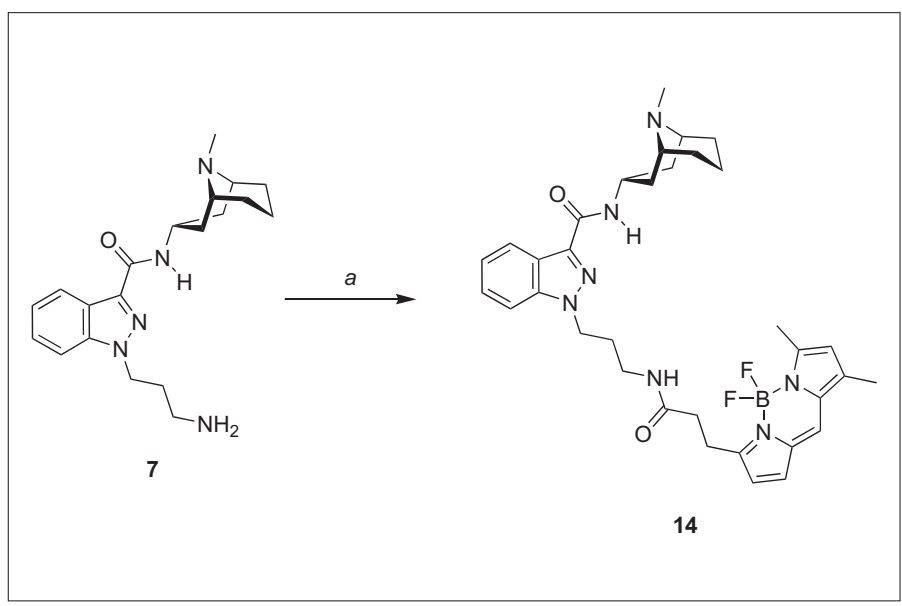

Scheme 2. Synthesis of fluorescent ligand BFL-GR (14). Reagents and conditions: (a) ${ }^{i} \mathrm{Pr}_{2}$ EtN, BODIPY FL SE, DMF, r.t.. greatly reduced environmental and cost impacts compared with radioligand binding assays. ${ }^{5]}$ Furthermore, fluorescent high-affinity ligands can be interesting for imaging applications such as receptor localisation and the study of receptor trafficking in living cells.

We have recently reported the synthesis and biological characterisation of a high-affinity fluorescent ligand for the human $5-\mathrm{HT}_{3} \mathrm{AR},{ }^{[6]}$ which is based on the high-affinity $5-\mathrm{HT}_{3} \mathrm{R}$ antagonist granisetron $^{[7]}$ (1, Fig. 2). Due to the lack of granisetron structure-activity data in the public domain we first needed to identify a suitable tethering position for potentially bulky biophysical tags on the granisetron core. We synthesised fourteen different granisetron derivatives with differently sized functional group on the granisetron core (Fig. 2) and evaluated their affinities for the human 5-HT $\mathrm{AR}$. As a representative example, the synthesis of 7-methoxy derivative 5b is shown in Scheme 1 and it was accomplished starting from anisidine 8 which was transformed into indazole 9 using a classic route. ${ }^{[8]}$ A 2-(trimethylsilyl)ethoxymethyl (SEM) group was attached selectively to $\mathrm{N}(2)$ of 9 which was followed by a SEM-directed C(3) lithiation and subsequent reaction with an ester group donor. [9] Protecting group cleavage, $\mathrm{N}(1)$ methylation and subsequent ester hydrolysis furnished indazole carboxylic acid 11 which was coupled with bicyclic amine $\mathbf{1 2}$ to yield amide $\mathbf{5 b}$. The amine $\mathbf{1 1}$

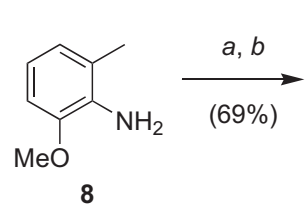<smiles>COc1cccc2c(C(=O)NC3CCC4CCCN(C)C4C3)nn(C)c12</smiles>

$5 b$<smiles>COc1cccc2cn[nH]c12</smiles>

9

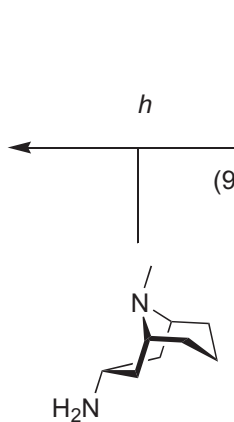

12<smiles>CCOC(=O)c1n[nH]c2c(OC)cccc12</smiles>

10
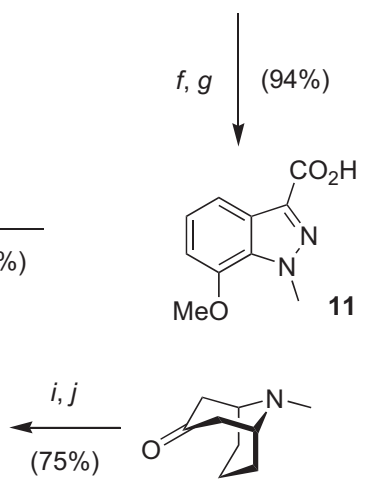

13

Scheme 1. Synthesis of compound 5b. Reagents and conditions: (a) aq. $\mathrm{HBF}_{4}$; aq. $\mathrm{NaNO}_{2}, \mathrm{O}^{\circ} \mathrm{C}$; (b) KOAc, 18 -crown-6, $\mathrm{CHCl}_{3}$, r.t.; (c) ${ }^{\mathrm{c}} \mathrm{Hex}_{2} \mathrm{NMe}$, SEM-Cl, THF, r.t.; (d) ${ }^{n} \mathrm{BuLi}$, THF, $-78^{\circ} \mathrm{C}$; $\mathrm{CNCO}_{2} \mathrm{Et}$; (e) $2 \mathrm{M} \mathrm{HCl}$, EtOH, r.t.; (f) $\mathrm{KO}{ }^{t} \mathrm{Bu}$, THF, $0{ }^{\circ} \mathrm{C}$; $\mathrm{Mel}$, r.t.; (g) $2 \mathrm{M} \mathrm{NaOH}, \mathrm{MeOH}, 0{ }^{\circ} \mathrm{C}$; (h) DCC, $\mathrm{HOBt}, 12, \mathrm{CH}_{2} \mathrm{Cl}_{2} / \mathrm{DMF} 3: 1$, r.t.; (i) $\mathrm{NaOAc}, \mathrm{HONH}_{2} \bullet \mathrm{HCl}$, $\mathrm{MeOH}$, r.t.; (j) $\mathrm{LiAlH}_{4}, \mathrm{H}_{2} \mathrm{SO}_{4}$, THF, $30^{\circ} \mathrm{C}$.

was prepared from the corresponding bicylic ketone 13 using an oxime formation and reduction sequence. ${ }^{[10]}$ We have discovered that all methoxy derivatives $\mathbf{2 b}-$ $\mathbf{5 b}$ are fluorescent which might open new interesting avenues for further investigations. The affinities of compounds 2-7 for the human $5-\mathrm{HT}_{3} \mathrm{AR}$ were assessed by competition with radiolabelled $\left[{ }^{3} \mathrm{H}\right]$ granisetron and the data showed that the $\mathrm{N}(1)$ and $\mathrm{C}(7)$ positions of the indazole and the $\mathrm{C}(9)$ position of the granatane of granisetron are the most tolerant regarding substitution (e.g. 5c: $K_{\mathrm{i}}=0.23 \pm 0.03$ $\mathrm{nM} ; 6: K_{\mathrm{i}}=59.3 \pm 0.8 \mathrm{nM} ; 7: K_{\mathrm{i}}=1.89 \pm$ $0.33 \mathrm{nM})$. To confirm the validity of these binding results, we linked a 4,4-difluoro4-bora-3a,4a-diaza-s-indacene (BODIPY) fluorophore to the N(1) position of granisetron (Scheme 2) to create fluorescent analogue BFL-GR (14). Experiments showed that 14 binds with high affinity to $5-\mathrm{HT}_{3} \mathrm{AR}\left(K_{\mathrm{i}}=2.80 \pm 0.72 \mathrm{nM}\right)$ and can be visualised in mammalian cells expressing the h5-HT 3 AR (Fig. 3). Similar images have previously been obtained using fluorescein, rhodamine $6 \mathrm{G}$ and cyanine Cy5 conjugates of ondansetron, another high-affinity 5-HT R antagonist.[11] Currently, we are exploring if BFL-GR would be a suitable tracer ligand in a fluorescence polarisation assay.

Fluorescence polarisation assays are easily miniaturised and can be executed in a homogeneous (mix-and-read) fashion, thus leading to assays that are truly highthroughput. Boyd and coworkers have recently reported the synthesis of potential fluorescence polarisation tracer ligands 16a-c based on dofetilide (15), a known high-affinity channel blocker of the hERG channel (Fig. 4). ${ }^{[12]}$ The human ether-a-gogo-related gene (hERG) potassium channel is a voltage-gated ion channel which is expressed in the heart muscle. It is critical for repolarisation of cardiac tissue dur- 

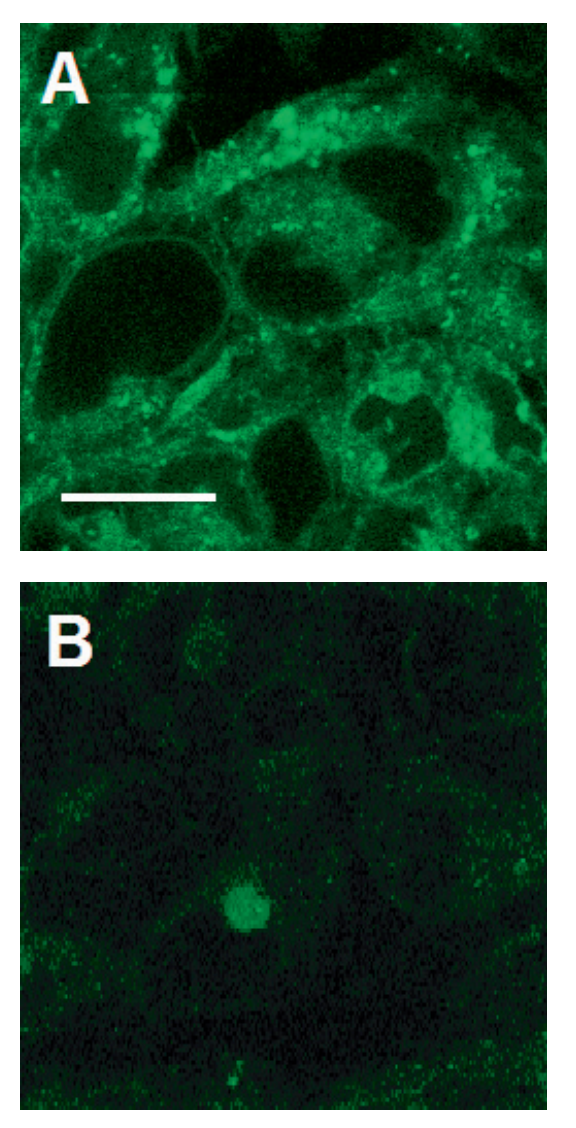

Fig. 3. BFL-GR (14) labeling of HEK293 cells stably transfected with $\mathrm{h} 5-\mathrm{HT}_{3} \mathrm{AR}$. Cells were incubated with (B) or without (A) quipazine, a competitive $5-\mathrm{HT}_{3} \mathrm{R}$ ligand. A: Clusters of receptors clearly present in many cells, unlabelled areas are nuclei. B: Quipazine has displaced BFL-GR from its binding sites leaving only weak autofluorescence. Scale bar represents $20 \mu \mathrm{m}$.

ing the heart beat cycle and it has been demonstrated that a number of marketed therapeutic drugs have off-target affinity for the hERG channel which can lead to a potentially lethal cardiac arrhythmia. Con- sequently, every drug candidate has to be tested for unwanted hERG channel affinity. The electrophysiological patch-clamp assay is an industry standard for measuring functional hERG channel blockage by drug candidates or lead compounds but in its current format this assay is not suitable for high-throughput screening. Hence, there are clear incentives to move to fluorescence-based assays which are more amenable for high-throughput screening, however, a major challenge is the need to develop a fluorescent ligand that has high affinity for the receptor of interest and that gives a robust fluorescence polarisation signal when bound.

\section{Photoaffinity Ligands}

Photoaffinity labelling has greatly increased the capability of specific tagging of proteins and it is a valuable strategy in target identification where the compound of interest has only a moderate affinity for its protein or receptor target. ${ }^{[13]}$ The three most commonly used photocrosslinking groups that have demonstrated utility in cellular systems are aryl azides 17, benzophenones 19 and diazirines 21 (Scheme 3). One has to appreciate that these photophores display different photochemistries which determine crosslinking efficiency and specificity of the corresponding photoaffinity probe. The azido functionality has been a popular choice due to its small size and ease of introduction, however, aryl azides have to be photoactivated at short wavelength light (254-280 $\mathrm{nm})$ to generate reactive nitrenes $\mathbf{1 8}$, which can cause damage to biomolecules. In contrast, activation of benzophenones occurs at longer wavelengths $(350-365 \mathrm{~nm})$ to produce reactive diradical 20. Note that benzophenone photolysis is reversible and may involve many excitation-relaxation cycles until a favourable conformation for covalent bond formation is achieved. In addition, the benzophenone diradical 20 is known to exhibit a strong preference to react with methionine residues which can lead to biased results. Diazirines are synthetically more demanding and require a multistep synthesis. They can be photoactivated by long wavelength light (360-365 $\mathrm{nm})$, resulting in formation of carbene 22, which inserts very quickly into $\mathrm{C}-\mathrm{H}$ and heteroatom-H bonds. Crosslinking efficiency may be decreased by the ability of carbene $\mathbf{2 2}$ to react with water and to rearrange to a diazo isomer sideproduct. ${ }^{[14]}$

Casida and coworkers have developed aryl azides 23 and 24 in order to map the elusive agonist binding site of nAChR receptors (Fig. 5). ${ }^{[15]}$ Two types of structurally similar nicotinic agonists have very different biological and physicochemical properties: neonicotinoids, including important insecticides, are selective for insects and their nAChRs, whereas nicotinoids are selective for mammalian systems. Homologous acetylcholine binding protein (AChBP) was used as surrogate for the extracellular ligand-binding domain of the $\mathrm{nAChR}$, and covalently modified with radiolabelled photoaffinity probes $\mathbf{2 3}$ and $\mathbf{2 4}$. The site of covalent modification could be established by collision-induced dissociation (MS-MS) and Edman degradation of digestion fragments of the modified AChBP. The data showed that both photoaffinity probes labelled the same binding site residues. Subsequent docking studies exploited this information and indicated that, albeit occupying the same binding site, neonicotinoids adopt a unique inverted pharmacophore position compared to nicotinoids.

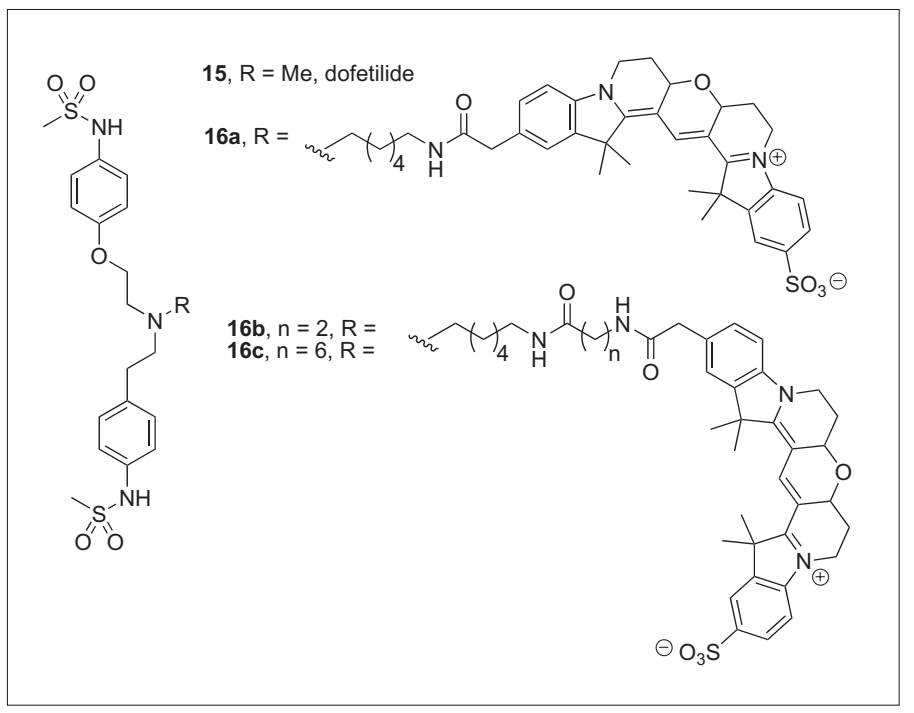

Fig. 4. hERG channel blocker 15 and fluorescent Cy3B analogues $16 a-c$.

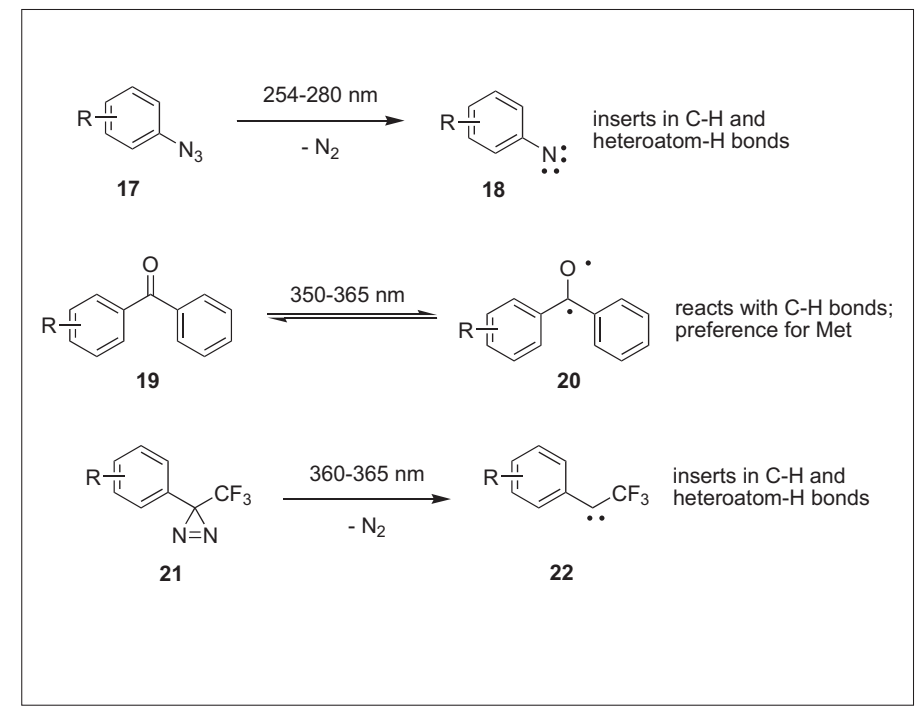

Scheme 3. Photochemical reactions of major photophores used for photoaffinity labelling. 


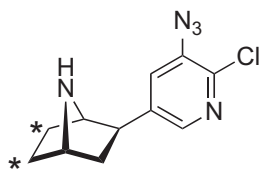

23

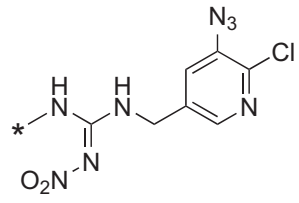

24
Fig. 5. Nicotinoid (23) and neonicotinoid (24) photoaffinity probes. Asterisks indicate positions of tritium.

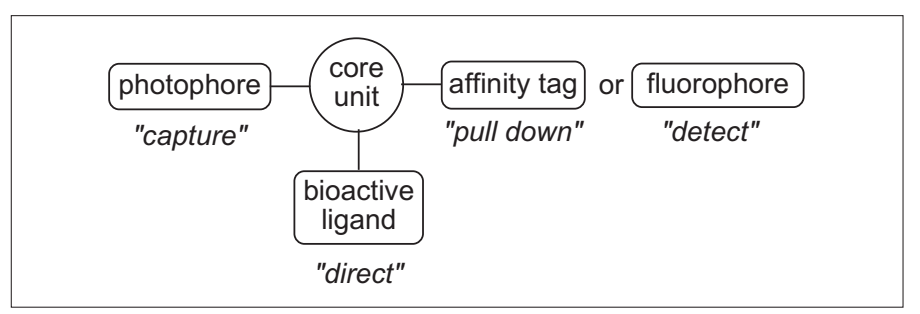

Fig. 6. Generalised design for all-in-one multifunctional probes.

\section{Multifunctional Probes}

In recent years several examples of more sophisticated all-in-one molecular probes have emerged which contain the bioactive ligand, a photoreactive group and a fluorophore or affinity tag (e.g. biotin). ${ }^{[16]}$ This approach requires a central multifunctional core unit (Fig. 6) in order to connect the building blocks. Amino acids like lysine, tyrosine, serine, glutamate and aspartate with three functional groups are available in many protecting group combinations and are therefore popular scaffolds. Photoaffinity probes typically contain radioisotopes as sensitive means of detection (see $\mathbf{2 3}$ and $\mathbf{2 4}$ ), however, special infrastructure, training and equipment is required in order to conduct the radiosynthesis and to handle such probes. More recent probes therefore have fluorophore often in combination with a biotin tag for affinity-based purification ('pulldowns').

Li et al. have recently described the synthesis of trimodular activity-based probe 25 targeting GABA $_{\mathrm{B}}$ receptors (Fig. tags linked to the target-finding ligand,
7).[17] This probe comprises a $\mathrm{GABA}_{\mathrm{B}}$ receptor binding moiety, a fluorophore and a diazirine photoaffinity tag, and exhibits high photoaffinity labelling specificity of $\mathrm{GABA}_{\mathrm{B}}$ receptors on living cells.

Obviously, there is a risk of losing biological activity when several bulky biophysical tags are added to a high-affinity ligand. In practice, a rigorous optimisation of the multifunctional probe is often needed (variation of linker length, scaffold, photoaffinity group, fluorophore) in order to balance useful biological activity, good modification efficiency and target selectivity.

An alternative strategy is to equip molecular probes with small chemoselective functional groups such as alkynes, azides or ketones, which offer the possibility of using biocompatible chemistries ${ }^{[18]}$ fol-

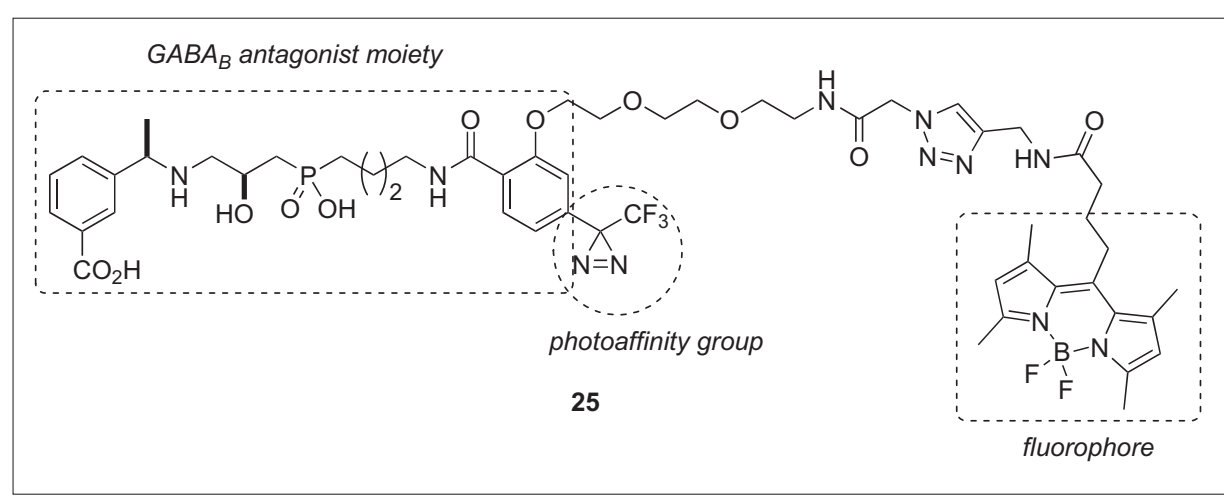

Fig. 7. Structure of trimodular $\mathrm{GABA}_{\mathrm{B}}$ receptor probe 25 .

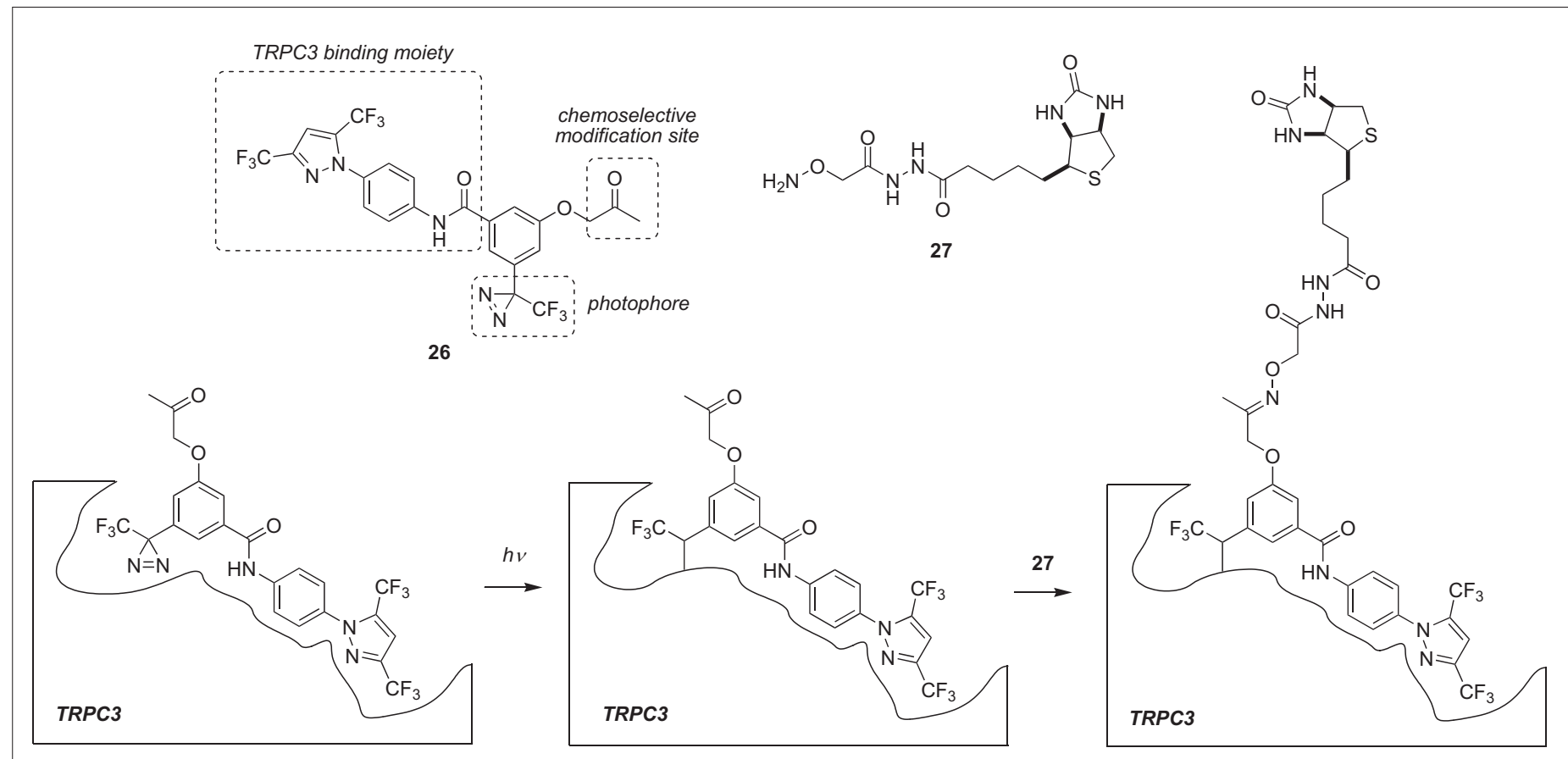


lowing the photoaffinity step in order to conjugate fluorophores or affinity tags. This post-photoaffinity labelling modification (P-PALM) approach was successfully applied in the development of compact bifunctional probe $\mathbf{2 6}$ directed against the TRPC3 channel (Scheme 4). ${ }^{[19]}$ The photoreaction forms a covalent bond between 26 and the TRPC 3 channel and subsequent reaction with hydroxylamine $\mathbf{2 7}$ introduces a biotin tag that allows isolation of modified protein by means of avidin pulldown.

\section{Concluding Remarks}

The number of organic chemists venturing into neuroscience is on the rise. Cleverly designed molecular probes are very valuable tools to investigate the structure and function of ion channel receptors. These tools represent a complementary strategy to traditional biological approaches and might yield a new and rewarding angle to look at ion channel function. There are numerous ion channel receptors which are difficult to clone or to isolate from native tissue and whose binding sites for small molecules are unknown. Highaffinity biophysical probes could make significant contributions in such cases, in particular if the ion channel of interest can be studied in living cells. Ligand-directed chemical modifications avoid the necessity of introducing mutations in order to conjugate fluorophores or affinity tags in a site-specific manner which is again advantageous for receptors which are difficult to clone. Better understanding of ion channel structure and function will ultimately lead to better and more selective drugs.

\section{Acknowledgments}

The author thanks the EPSRC (EP/ E042139/1) and the Wellcome Trust (081925/Z/07/Z) for financial support. The award of a SNSF Professorship to M. L. from the Swiss National Science Foundation is gratefully acknowledged.

Received: February 8, 2010

[1] F. M. Ashcroft, 'Ion Channels and Disease', Academic Press, New York, 2000.

[2] D. C. Reeves, S. C. R. Lummis, Mol. Membr. Biol. 2002, 19, 11 .

[3] a) K. Brejc, W. J. van Dijk, R. V. Klaassen, M. Schuurmans, J. van der Oost, A. B. Smit, T. K. Sixma, Nature 2001, 411, 269; b) C. D. Dellisanti, Y. Yao, J. C. Stroud, Z.-Z. Wang, L. Chen, Nat. Neurosci. 2007, 10, 953; c) R. J. C. Hilf, R. Dutzler, Nature 2008, 452, 375; d) N. Unwin, J. Mol. Biol. 2005, 346, 967.

[4] For 5-HT ${ }_{3}$ AR homology models, see a) D. C. Reeves, M. F. R. Sayed, P.-L. Chau, K. L. Price, S. C. R. Lummis, Biophys. J. 2003, 84, 2338; b) A. J. Thompson, K. L. Price, D. C. Reeves, S. Ling Chan, P.-L. Chau, S. C. R. Lummis, $J$. Biol. Chem. 2005, 280, 20476; c) P. R. Joshi, A. Suryanarayanan, E. Hazai, M. K. Schulte, G. Maksay, Z. Bikadi, Biochemistry 2006, 45, 1099; d) D. Yan, M. M. White, Mol. Pharmacol. 2005, 68, 365 .

[5] A. Dorn, F. Hermann, A. Ebneth, H. Bothmann, G. Trube, K. Christensen, C. Apfel, J. Biomol. Screen. 2005, 10, 339.

[6] S. K. Vernekar, H. Y. Hallaq, G. Clarkson, A. J. Thompson, L. Silvestri, S. C. R. Lummis, M. Lochner, J. Med. Chem., 2010, 53, 2324.

[7] J. Bermudez, C. S. Fake, G. F. Joiner, K. A. Joiner, F. D. King, W. D. Miner, G. J. Sanger, J. Med. Chem. 1990, 33, 1924.

[8] a) R. A. Bartsch, I. W. Yang, J. Hetercycl. Chem. 1984, 21, 1063; b) P. Schumann, V. Collot, Y. Hommet, W. Gsell, F. Dauphin, J. Sopkova, E. T. MacKenzi, D. Duval, M. Boulouard, S. Rault, Bioorg. Med. Chem. Lett. 2001, 11, 1153.

[9] G. Luo, L. Chen, G. Dubowchik, J. Org. Chem. 2006, 71, 5392.

[10] P. Donatsch, G. Engel, B. Hügi, B. P Richardson, P. A. Stadler, G. Breuleux, US 5,017,582, 1991.
[11] T. Wohland, K. Friedrich, R. Hovius, H. Vogel, Biochemistry 1999, 38, 8671.

[12] D. H. Singleton, H. Boyd, J. V. Steidl-Nichols, M. Deacon, M. J. de Groot, D. Price, D. O. Nettleton, N. K. Wallace, M. D. Troutman, C. Williams, J. G. Boyd, J. Med. Chem. 2007, 50, 2931.

[13] a) Y. Hatanaka, Y. Sadakane, Curr. Top. Med. Chem. 2002, 2, 271; b) B. J. Leslie, P. J. Hergenrother, Chem. Soc. Rev. 2008, 37, 1347; c) Y. Tanaka, M. R. Bond, J. J. Kohler, Mol. Biosyst. 2008, 4, 473.

[14] J. Brunner, H. Senn, F. M. Richards, J. Biol. Chem. 1980, 255, 3313.

[15] a) M. Tomizawa, D. Maltby, K. F Medzihradszky, N. Zhang, K. A. Durkin, J. Presley, T. T. Talley, P. Taylor, A. L. Burlingame, J. E. Casida, Biochemistry 2007, 46, 8798; b) M. Tomizawa, T. T. Talley, D. Maltby, K. A. Durkin, K. F. Medzihradszky, A. L. Burlingame, P. Taylor, J. E. Casida, Proc. Natl. Acad. Sci. USA 2007, 104, 9075.

[16] a) E. Weerapana, A. E. Speers, B. F. Cravatt, Nat. Protoc. 2007, 2, 1414; b) T. Kan, Y. Kita, Y. Morohashi, Y. Tominari, S. Hosoda, T. Tomita, H. Natsugari, T. Iwatsubo, T. Fukuyama, Org. Lett. 2007, 9, 2055; c) X. Z. Zhao, E. A. Semenova, C. Liao, M. Nicklaus, Y. Pommier, T. R. Burke, Jr., Bioorg. Med. Chem. 2006, 14, 7816.

[17] X. Li, J.-H. Cao, Y. Li, P. Rondard, Y. Zhang, P. Yi, J.-F. Liu, F.-J. Nan, J. Med. Chem. 2008, 51, 3057.

[18] a) M. Köhn, R. Breinbauer, Angew. Chem., Int Ed. 2004, 43, 3106; b) A. Deiters, P. G. Schultz, Bioorg. Med. Chem. Lett. 2005, 15, 1521.

[19] S. Kiyonaka, K. Kato, M. Nishida, K. Mio, T. Numaga, Y. Sawaguchi, T. Yoshida, M. Wakamori, E. Mori, T. Numata, M. Ishii, H. Takemoto, A. Ojiida, K. Watanabe, A. Uemura, H. Kurose, T. Morii, T. Kobayashi, Y. Sato, C. Sato, I. Hamachi, Y. Mori, Proc. Natl. Acad. Sci. USA 2009, 106, 5400. 